\title{
International Journal of Medical Science and Health Research
}

Vol. 5, No. 01; 2021

ISSN: 2581-3366

\section{Voluntary Medical Male Circumcision (VMMC) Among Males in Zambezi Region, Namibia}

\author{
Rosalia Nairenge ${ }^{1}$, Linda N Lukolo*1 2 \\ School of Nursing, University of Namibia \\ Department of Family and community medicine, School of Medicine, University of Namibia \\ Namibia
}

doi: 10.51505/IJMSHR.2021.5109

URL: http://dx.doi.org/10.51505/IJMSHR.2021.5109

\begin{abstract}
Male circumcision is one of the popular intervention methods that is fully supported by modern health practitioners to curb the spread of human immunodeficiency virus (HIV) that leads to Acquired immune deficiency Syndrome (AIDS) with estimate of $60 \%$ and to reduce the risk of some sexual transmitted infections, cervical and penile cancer. The purpose of this study was to assess the knowledge, attitudes, practices and responsiveness of males towards voluntary medical male circumcision in Zambezi Region. This was a cross sectional study among men from 15 years and older in five randomly selected constituencies of Zambezi Region. Participants were selected using probability sampling method. Data was collected using structured questionnaires, consisted of four sections, namely: sociodemographic, level of knowledge, attitudes towards VMMC and responsiveness. The data was entered into Microsoft excel sheet and analyzed with Epi-info 7.2 software. Frequencies and proportions were generated and bivariate analysis were performed to determine associations. A total number of 379 participants were involved in the study. Most participants were between the age group of 20-29 years $124(33 \%)$, majority of participants $292(77 \%)$ resides in rural area, mostly in Linyanti constituency 144(38\%). Most participants indicated being single $256(68 \%)$, and a total of 365 $(95 \%)$ can read and write. Majority had adequate knowledge 354(95\%) and positive attitudes 330 $(87 \%)$ towards VMMC. Association of circumcision status with level of knowledge was $(\mathrm{OR}=0.1, \mathrm{CL}=0.08-0.50) \mathrm{p}$-value $=0.0004$, type of attitude $(\mathrm{OR}=0.1, \mathrm{CL}=0.07-0.29) \mathrm{p}$-value $=$ 0.0001 and this was all significant. This study concluded that participants had adequate knowledge and positive attitudes towards VMMC, however there are some men with lack of knowledge and negative attitudes towards the VMMC program. Therefore, the study recommends for more education and awareness campaigns on VMMC in order to facilitate behavior change among this group and enhance the performance of the VMMC program in the region.
\end{abstract}

Keywords: Voluntary medical male circumcision, HIV/AID, Knowledge on VMMC, practice on VMMC, attitudes on VMMC. 


\section{International Journal of Medical Science and Health Research}

Vol. 5, No. 01; 2021

ISSN: 2581-3366

\section{Introduction}

Male circumcision (MC) is a surgical removal of the foreskin (the retracted fold of tissues that covers the head) of the penis performed by trained health professionals with specialized sterile equipment in a sterile environment. The aim of medical male circumcision is to reduce the transmission of Human Immunodeficiency Syndrome (HIV), to reduce the risk of some sexual transmitted infections, reduce partner's risk of cervical cancer, lowers risk of penile cancer and improves penile hygiene. Global statistics indicates that Sub-Saharan Africa is the most affected with the Human Immunodeficiency Virus (HIV) and Acquired Immunodeficiency Syndrome (AIDS). According to World Health Organization (WHO), more than 70 million people have been infected with the HIV worldwide and about two third of these infections occurred in subSaharan Africa. About 35 million people have died of HIV/AIDS at the end of 2016 (CDC, 2018).

Three randomized controlled trial (RCT) in Uganda, Kenya and South Africa were conducted to establish the efficacy of male circumcision and HIV acquirement, these studies reported that circumcised men were less likely to get infected with HIV compared to uncircumcised men with reduction estimate of 60\% (WHO, 2009). Since 2007, WHO and the joint United Nations Programme on HIV/AIDS (UNAIDS) recommended that Voluntary Medical Male Circumcision (VMMC) should be an additional strategy to the prevention package for HIV prevention in settings with high HIV prevalence and low levels of male circumcision (On, Circumcision, \& Hiv, 2010). VMMC means that males should go for medical male circumcision at their own free will and not by force. Male circumcision is common in some African countries especially in North and West Africa. Most of these countries have high Male circumcision prevalence, in Ethiopia about $99 \%$ of men are circumcised and $86 \%$ are circumcised in Ghana. In contrast, in southern Africa male circumcision is less common, where self-reported prevalence is around 18 $\%$ in countries like Botswana, South Africa, Zambia, Zimbabwe and Namibia (Unaids, 2007).

Namibia is one of the fourteen African countries that adopted the VMMC program considering its HIV profile and low rates on male circumcision. The country is ranked among the 10 countries with the highest HIV prevalence levels in the world reports WHO (2012). An estimated 178000 people are living with HIV in Namibia (The Namibia Ministry of Health and Social Services \& Namibia Statistics Agency, 2014). Although availability of antiretroviral therapy and other HIV prevention and control measures have been put in place, more new HIV infections keep occurring. VMMC was adopted to be used in conjunction with other HIV prevention methods such as HIV testing and counselling, correct and consistence use of female and male condoms, provision of antiretroviral treatment for people living with HIV in discordant couple. Scaling up of VMMC began in 2009 in most Namibian Regions with an estimate of 80\% of adult and newborn males circumcised by the year 2015 (would have averted 35000 adult's HIV infections between 2009-2025) (2). Regional targets were set based on a Regional analysis of MC prevalence, Regional demographics and HIV prevalence (2). Scaling up of VMMC in Zambezi Region started in 2013, whereby the region was given an estimate target to perform 15 477 MC (15-49 years) by the year 2016. Zambezi Region is one of the fourteen regions in Namibia.it is located in the extreme northeast of Namibia and has a population of 106318 of 


\section{International Journal of Medical Science and Health Research}

Vol. 5, No. 01; 2021

ISSN: 2581-3366

which 51\% are females and 49\% are males (Steytler, 2014). The region is divided into eight electoral constituencies and the most language spoken is Silozi.

\section{Study rationale}

Zambezi Region was reported among the regions with the lowest rates (less than 10\%) of MC in Namibia (On et al., 2010) despite high prevalence of HIV epidemic. Despite the implementation of VMMC program as an additional strategy for HIV prevention in Zambezi region, there is still a low uptake of male circumcision even though awareness campaigns on MC as a strategy for HIV prevention is ongoing. The region only managed to circumcise 8751 men (at the end of June 2018) out of the 15477 target representing $56 \%$ coverage against $80 \%$ in the 3 -year period (2013-2016) (4,8). This study is therefore aimed to asses the attitudes, knowledge, practices and responsiveness on voluntary medical male circumcision in Zambezi region.

\section{Methods}

The study design used was a quantitative, cross-sectional survey to assess the knowledge, attitudes, practices and responsiveness of males towards voluntary medical male circumcision in Zambezi Region.

\subsection{Study population}

The study population in this research were males from the age of 15 years and above, both circumcised and non-circumcised who are residing in Zambezi Region.

\subsection{Sampling method}

The researcher used probability sampling by means of multi-stage sampling.

Sampling stages involved:

Stage 1: constituencies: Out of eight (8) electoral constituencies in Zambezi region, the researcher selected five (5) constituencies randomly, by wrote down the names of all constituencies on eight pieces of papers and fold them and put in a bowl, five peace of papers were taken randomly from the bowl.

Stage 2: primary sampling unit (PSU): There are three hundred and thirty-seven (337) primary sampling units (clusters) in all the eight constituencies of Zambezi Region. The number of primary sampling units where obtained from the map that was provide by the Namibia statistics Agency. The researcher used cluster sampling methods to select thirty (30) primary sampling unit out of three hundred and thirty-seven (337) primary sampling units (clusters) in all the eight constituencies of Zambezi Region.

Stage 3: households: Households from the chosen primary sampling units were selected randomly to participate in the study. The researcher walked from house to house (from the selected primary sampling units) to identify participants that were eligible for the study, if in a certain house there was no male eligible, the researcher walked to the next house. Fourteen (14) participants who were 15 years and above were selected from each primary sampling unit to be included in the study on to meet required sample size. 


\section{International Journal of Medical Science and Health Research}

Vol. 5, No. 01; 2021

ISSN: 2581-3366

\subsection{Research Instruments and Data Collection Procedure}

Structured questionnaire was developed and used for data collection. It was translated into the local language commonly spoken in the region which is Silozi. Structured questionnaire was used for data collection, it was consisted of four sections, namely; sociodemographic, Level of knowledge, attitudes towards VMMC, practices and responsiveness. Prior to data collection, two research assistants were identified from Zambezi region and trained by the lead researcher on the concept, procedures and the data collection tools of the study.

\section{Data Analysis}

Data were entered in Microsoft excel for coding and cleaning. Analysis were done using Microsoft excel and Epi-info 7 software. Sociodemographic information was analyzed using frequencies and proportions. Level of knowledge were determined using scores. Each question on knowledge in this section was assigned a score of " 1 " for a "true" or 0 for a "false". A series of seven questions were asked on knowledge and overall score were calculated for each participant. Attitudes towards VMMC were assessed using scores of 1 for "agree', 0 for "don't agree'. A series of five questions were asked to participants. Overall scores were calculated for every participant, if overall scores are three or more that indicated positive attitude and if two or less it indicated negative attitudes. Responses on questions on Practice and responsiveness were assessed by calculating frequencies and proportions. Statistical significance was determined at $\mathrm{P}<0.05$ significance $(95 \%$ confidence interval) was set for all statistical procedure.

\section{Ethical considerations}

Prior commencement of study, approval was obtained from relevant authorities; the University of Namibia and Ministry of Health and Social Services.

4.1 Respect for participants and their human rights. Each Participant were provided with a consent form and the researcher explained the purpose and procedure of the study before the participant agreed to sign the consent form. For the participants below the ages of 18, parents or guardians were requested to provide consent by signing on the consent form on their behalf. Participation in the study was voluntarily and participants were informed to withdraw from the study if they felt uncomfortable answering the questions.

4.2 Non- Maleficence. Participants' confidentiality were be insured by practicing anonymity; no names were written on the questioners. The questioners had serial numbers and there was no link between the respondents to the questioners. The data collection tools were kept safe and participant information were not be disclosed.

4.3 Justice. All males from ages 15 years and above residing in Zambezi region regardless of race, cultural beliefs, social status or educational background had equal opportunity to participate in the study. 


\section{International Journal of Medical Science and Health Research}

Vol. 5, No. 01; 2021

ISSN: $2581-3366$

4.4 Beneficence. The study provided understanding regarding the knowledge, attitudes and practices towards medical male circumcision as an HIV prevention strategy among males in Zambezi region, and identify gaps and area for improvement of the VMMC program in the region.

\section{Results of the study}

A total of 379 males participated in the study. The participants were categorized in different age groups ranged from 15 to 60 years. Majority of participants were among the ages group of 20-29 years 33\% ( $n=124), 22 \%(n=103)$ between ages $15-19$ years, 22\% $(n=82)$ were between 30-39 years and the least was among 40 years and above $18 \%(n=70)$. A total of $68 \%(n=256)$ were not married, $27 \%(n=102)$ were married, those who were divorced were $3 \%(n=12)$ and the least were widower $1 \%(\mathrm{n}=4)$. Majority of the participants were residing in rural area $77 \%(\mathrm{n}=292)$ and $23 \%(\mathrm{n}=89)$ in urban. Majority of the participants could read and write $95.5 \%(\mathrm{n}=362)$ and those who could not read and write were $5 \%(n=17)$. Most of the participants had acquired at least a secondary education $61 \%(\mathrm{n}=230), 25 \%(93)$ acquired tertiary education while 5\% $(\mathrm{n}=17)$ had no formal education. Most participants responded to be unemployed $62 \%(\mathrm{n}=236)$ and $38 \%(\mathrm{n}=143)$ were employed.

Table 1. Knowledge level about medical male circumcision, Zambezi Region

\begin{tabular}{|l|l|l|}
\hline Knowledge level & $\begin{array}{l}\text { Frequencies } \\
(\mathbf{N})\end{array}$ & $\begin{array}{l}\text { Percentages } \\
(\mathbf{\%})\end{array}$ \\
\hline Adequate & 354 & 93 \\
\hline Inadequate & 25 & 6.6 \\
\hline Total & 379 & 100 \\
\hline
\end{tabular}

\subsection{Medical male circumcision practices and responsiveness}

A total of $97 \%(n=360)$ responded that male circumcision is practiced at health facilities. The majority of the respondents $84 \%(n=318)$ knew health facilities near their residence where medical male circumcision is performed however $16 \%(\mathrm{n}=61)$ had no idea where it is performed. A total of $62 \%(n=234)$ responded that they were circumcised while $38 \%(n=145)$ of participants were not circumcised. From the 62\% $(n=234)$ participants who responded that they are circumcised, about $50 \%(\mathrm{n}=117)$ of them indicated that they were circumcised between ages of 5 to 18 years, while $47 \%(\mathrm{n}=109)$ undergone circumcision between ages 19 and above, about 3\% $(n=7)$ were not sure at what age they were circumcised. Moreover, they were further asked where was circumcision performed, $94(\mathrm{n}=219)$ responded that is was performed at health facility, 5\% $(n=12)$ they were circumcised at the traditional and $1 \%(n=3)$ did not know at which place was it performed. majority $28 \%(n-41)$ of the participants who were not circumcised indicated that they did not get circumcised because they were afraid of pain $28 \%(n=41)$ and $26 \%(n-37)$ indicated that they don't want $26 \%(n=37) 10 \%$ respondents said they don't have access $10 \%$ $(\mathrm{n}=15)$ to health facilities were medical male circumcision is performed. Some participants provided other reasons such as: they don't want female health workers to attend to them, healing 


\section{International Journal of Medical Science and Health Research}

Vol. 5, No. 01; 2021

ISSN: 2581-3366

process after the procedure takes long and that interferes with their businesses. Majority $96 \%$ $(\mathrm{n}=364)$ responded that they would recommend their male relatives or friends to be circumcised at a health facility, while others responded that they would not $2 \%(\mathrm{n}=5)$.

All the 379 participants were asked if they knew about HIV/AIDS: A total of 96\% ( $\mathrm{n}=364)$ responded that they know information about HIV while 4\% ( $n=14)$ responded that they do not know anything about HIV. All participants were further asked if they have ever been tested for HIV before at any health facilities or centers providing HIV tests, $83 \%(n=315)$ responded that they were tested however $18 \%(\mathrm{n}=64)$ said they have never been tested for HIV. From the $17 \%(n=64)$ who responded that they were never tested for HIV, 64\% $(n=41)$ said they would want to be tested for HIV, and they were given information about HIV and Where they can go for the HIV test. Moreover, 36\% $(n=24)$ responded that they still don't want to be tested for HIV, information on the importance of a person knowing their HIV status were explained to them. Association of sociodemographic characteristics and level of knowledge among respondents (illustrated below, table 3)

Table 2. Association of sociodemographic characteristics and level of knowledge among respondents

\begin{tabular}{|l|l|l|l|l|l|}
\hline Characteristics & IK N (\%) & $\begin{array}{l}\text { AK } \\
(\%)\end{array}$ & OR & 95\% CI & P-value \\
\hline Age groups & & & & & \\
\hline $15-19$ years & $9(2)$ & $94(25)$ & $*$ & & \\
\hline $20-29$ years & $7(2)$ & $117(30)$ & 1.6 & $0.56-4.68$ & 0.43 \\
\hline $30-39$ years & $6(2)$ & $78(21)$ & 1.2 & $0.42-3.9$ & 0.79 \\
\hline 40 yrs above & $9(2)$ & $59(16)$ & 0.6 & $0.22-1.72$ & 0.45 \\
\hline Residency & & & & & \\
\hline Rural & $24(6)$ & $268(71)$ & $*$ & & \\
\hline Urban & $6(2)$ & $81(21)$ & 1.2 & $0.49-33$ & 0.82 \\
\hline Literacy level & & & & & \\
\hline Can read \& write & $20(5)$ & $341(90)$ & & & \\
\hline Cannot read \& write & $6(2)$ & $12(3)$ & 0.12 & $0.04-0.37$ & 0.0006 \\
\hline Marital status & & & & & \\
\hline $\begin{array}{l}\text { Single } \\
\text { Married }\end{array}$ & $9(2)$ & $241(64)$ & $*$ & & \\
\hline $\begin{array}{l}\text { Others } \\
\text { (cohabiting/divorced) }\end{array}$ & $8(2)$ & $13(3)$ & 0.10 & $0.04-0.3$ & 0.0001 \\
\hline indicates a reference category & & & & \\
\hline
\end{tabular}




\section{International Journal of Medical Science and Health Research}

Vol. 5, No. 01; 2021

ISSN: 2581-3366

Age groups 20-29 years demonstrated to have adequate knowledge (30\%)compared to other age groups, however there was no statistical significance $(\mathrm{p}$-value $=0.43)$ in the association between age groups and the level of knowledge. The majority (71\%) of participants were from the rural area and they showed to have adequate knowledge compared to the ones in the urban area, no statistical significance ( $p$-value $=0.82$ ) in the association between area of residency and level of knowledge. The study revealed that participants who can read and write showed to have adequate knowledge (90\%), the odds of those who cannot read and write is $\mathrm{OR}=0.12$, there was statistical significance in the association between level of literacy and level of knowledge.

Table 3. Association of sociodemographic characteristics and level of attitudes among respondents

\begin{tabular}{|l|l|l|l|l|l|}
\hline Characteristics & NA N(\%) & PA N(\%) & OR & 95\% CI & P-value \\
\hline Age groups & & & & & \\
\hline 15-19 years & $7(2)$ & $96(25)$ & $*$ & & \\
\hline 20-29 years & $16(4)$ & $108(29)$ & 0.49 & $0.18-1.2$ & 0.18 \\
\hline 30-39 years & $10(3)$ & $72(19)$ & 0.52 & $0.18-1.46$ & 0.3 \\
\hline 40 yrs above & $16(4)$ & $54(14)$ & 0.23 & $0.09-0.6$ & 0.002 \\
\hline Residency & & & & & \\
\hline Rural & $47(12)$ & $245(65)$ & $*$ & & \\
\hline Urban & $8(2.1)$ & $79(21)$ & 1.89 & $0.88-4.4$ & 0.12 \\
\hline Literacy level & & & & & \\
\hline $\begin{array}{l}\text { Can read \& } \\
\text { write }\end{array}$ & $44(12)$ & $317(83)$ & $*$ & & \\
\hline $\begin{array}{l}\text { Cannot read \& } \\
\text { write }\end{array}$ & $8(2)$ & $10(3)$ & 0.19 & $0.07-0.58$ & 0.003 \\
\hline Marital status & & & & & \\
\hline Single & $25(7)$ & $231(60)$ & $*$ & & \\
\hline Married & $19(5)$ & $83(22)$ & 0.47 & $0.25-0.92$ & 0.03 \\
\hline $\begin{array}{l}\text { Others } \\
\text { (cohabiting/div } \\
\text { orced) }\end{array}$ & $9(2.3)$ & $12(3.2)$ & 0.14 & $0.05-0.39$ & 0.0001 \\
\hline
\end{tabular}

* indicates a reference category

Age groups 20-29 years demonstrated positive attitudes (29\%) compared to other age groups, however there was no statistical significance $(\mathrm{p}$-value $=0.18)$ in the association between age groups and the type of knowledge. Participants from rural area had positive attitudes (65\%), there was no statistical significance ( $\mathrm{p}$-value=0.12). Participants who can read and write showed to have positive attitudes (83\%), and this was statistically significance to the association between literacy level and the type of knowledge. Participants who were single demonstrated positive attitudes $(60 \%)$, the odd of married participants to have positive attitude were $\mathrm{OR}=0.47$, and this 


\section{International Journal of Medical Science and Health Research}

Vol. 5, No. 01; 2021

ISSN: 2581-3366

was statistical significant in the association between marital status and the level of attitude with the P-value of 0 .

Table 4. Association of circumcision status and level of knowledge among respondents.

\begin{tabular}{|l|l|l|l|l|l|}
\hline $\begin{array}{l}\text { Circumcision } \\
\text { status }\end{array}$ & IK N(\%) & AK N(\%) & or & 95\%CI & p-value \\
\hline Circumcised & $7(2)$ & $227(60)$ & $*$ & & \\
\hline $\begin{array}{l}\text { Not } \\
\text { circumcised }\end{array}$ & $18(5)$ & $126(33)$ & 0.2 & $0.08-0.50$ & 0.0004 \\
\hline
\end{tabular}

* indicates a reference category

Majority of circumcised (60\%) males had adequate knowledge compared to not circumcised (33\%) males with adequate knowledge. The odds of circumcised males among participants with inadequate knowledge is 0.2 times the odds of circumcised males with adequate knowledge. The results were statistical significant ( $\mathrm{p}$-value $=0.0004)$.

Table 5. Association of circumcision status and level of attitude

\begin{tabular}{|l|l|l|l|l|l|}
\hline $\begin{array}{l}\text { Circumcision } \\
\text { status }\end{array}$ & NA N(\%) & PA N(\%) & OR & 95\%CI & P-value \\
\hline Circumcised & $11(3)$ & $223(59)$ & $*$ & & \\
\hline $\begin{array}{l}\text { Not } \\
\text { circumcised }\end{array}$ & $37(10)$ & $108(28)$ & 0.1 & 0.07 & -0.0001 \\
\hline
\end{tabular}

* indicates a reference category

Majority of circumcised participants (59\%) showed positive attitudes, compared to noncircumcised participants. The odds of circumcised males among participants with negative attitudes are 0.1 times the odds of circumcised males with positive attitudes. The results were statistical significant $(\mathrm{p}$-value $=0.0001)$.

\section{Discussions}

VMMC can have a major impact on HIV epidemics in high-prevalence settings. VMMC services incorporate a package of prevention interventions, including safer sex education, education on and provision of condoms, HIV testing and the management of sexually transmitted infections. The current study aimed to assess the knowledge, attitudes, practices and responsiveness of males towards voluntary medical male circumcision in Zambezi Region. The researcher found out that males have heard about male circumcision and that it offers some advantages. It was also noted that respondents knew that male circumcision was done to prevent some sexually transmitted infections and maintain some penile hygiene. This is encouraging, as it suggests that HIV-related knowledge and benefits of circumcision are reaching the target populations. Findings in a study done by Faleye in South Africa in 2014 reported that, messages on HIV/AIDS prevention are having positive effect on sexual practices because it enhances people's 


\section{International Journal of Medical Science and Health Research}

Vol. 5, No. 01; 2021

ISSN: 2581-3366

knowledge (Faleye, Africa \& Attribution, n.d., 2014). Moreover, participants think that more education on VMMC is still required as they lack some information/knowledge about VMMC. Majority of participants were found to have adequate knowledge and positive attitudes towards VMMC. The study also highlighted that majority of males indicated that circumcision is mainly offered at health facilities and not traditionally.

A high number $(62 \%)$ of participants indicated that they were circumcised and about half of them were circumcised between the ages of 5 to 18 years, while the second majorities were circumcised from ages 19 years and older, some participants could not remember at what age they were circumcised, but they believed it was done at childhood ages. Many of the circumcisions were done at health facilities. A study done by Nanteze on knowledge, attitude and practice in Uganda showed that majority of participants were not circumcised and this affected the prevalence of male circumcision in the country (Nanteza et al., 2018). A similar study conducted in Zimbabwe by Chatora and others, assessing barriers to VMMC among males found that about $11 \%$ of the participants reported to have undergone circumcision while the majority were not (Hatzold K1, Mavhu W2, Jasi P1, Chatora K1, Cowan FM2, Taruberekera N3, Mugurungi O4, Ahanda K5, 2014). This study revealed that some participants were uncircumcised; Fear of pain is one of the common reasons indicated by the participants preventing them to go for the procedure, while others indicated that they do not have time to go for circumcision because the healing time takes long and this will interfere with their daily activities. Other participants pointed out that; they don't want at all, some don't have access to the facilities (distance is far from where they reside), don't want to be attended to by female nurses/ doctors, fear of taking HIV test. This concur with a study conducted by Sknolik and Tsui in Lesotho to identify the barriers to VMMC, some respondents pointed out that they were afraid of pain and did not support the idea of being attended to by female health workers as they don't feel comfortable (Sknolik, L., Tsui, S., Ashengo, T.A., Kikiya, V. \& Lukobo-Durrell, 2014). A similar study conducted by Chilungo in Malawi discovered that some barriers hindering the VMMC as fear of HIV test, fear of surgical procedure and pain (Chilungo, A. S., Sanudi, E., Honde, H., Kohler, I.V., MfutsoBengo, M., Bellos, D. \& Walkins, 2015).

A total of $96 \%$ participants were aware of HIV/AIDS. However, $17 \%$ responded that they have never been tested for HIV in their lives. While $83 \%$ have been previously tested for HIV at institutions were the HIV screening is provided. Participants who responded that they never had any HIV test in their lives were provided with information on the importance of knowing their HIV status and they indicated willingness to get tested for HIV. They were provided with information where to go for the test. Moreover, there were still participants who indicated that they do not want to get tested for HIV at all.

\section{Conclusion}

Zambezi Region is not a traditional circumcising Region, this study concludes that majority of males generally have adequate knowledge and positive attitudes towards VMMC, however there are still a few of males that needs more education regarding VMMC in order for them to change 


\section{International Journal of Medical Science and Health Research}

Vol. 5, No. 01; 2021

ISSN: 2581-3366

their behaviors towards VMMC. Information obtained from this study provides insight on knowledge, attitudes and responsiveness towards VMMC in the region. This may assist the policy makers on making decisions to improve the VMMC program in the region.

\section{Recommendations}

The researchers are recommending that MOHSS together with the relevant stakeholders should conduct ongoing campaigns on VMMC, disseminating accurate information on the benefits and the process of the programme as well as addressing misconceptions and fears of the people. The researchers also feels that the VMMC Regional (Zambezi) team should intensify outreach services as well as expanding it to areas hard to reach in order to involve those who cannot access the service due to long distances.

The outreach teams should communicate their schedule through local radio stations, traditional leaders and church leaders for people to be aware of when to expect them.

The VMMC regional team should incorporate behavior change programme in the existing community awareness campaigns since there is good awareness on VMMC.

\section{Acknowledgments}

The authors would like to thank for every one participated and contributed to this study made it possible, the University of Namibia for granted us the ethical clearance and the Ministry of Health and Social service at large for allowing the study to be conducted.

\section{References}

CDC. (2018). About HIV. Retrieved 4 July 2018, from https://www.cdc.gov

Chilungo, A. S., Sanudi, E., Honde, H., Kohler, I.V., MfutsoBengo, M., Bellos, D. \& Walkins, S. (2015). No TitleReport of a Qualitative Study on Barriers and Facilitators of Voluntary Medical Male Circumcision in Malawi. Retrieved 14 December 2018, from http://www.ehpsa.org/all-documents/general/62-vmmc-malawi

Faleye, A., Africa, S., Faleye, A., Africa, S., \& Attribution, C. (n.d.) (2014). Knowledge of HIV and benefits of male medical circumcision amongst clients in an urban area, 1-5. https://doi.org/10.4102/phcfm.v6i1.722

Hatzold K1, Mavhu W2, Jasi P1, Chatora K1, Cowan FM2, Taruberekera N3, Mugurungi O4, Ahanda K5, N. E. (2014). Barriers and motivators to voluntary medical male circumcision uptake among different age groups of men in Zimbabwe: results from a mixed methods study. Retrieved 20 December 2018, from https://www.ncbi.nlm.nih.gov/pubmed/24802746

Management, T. R. (2017). Voluntary Medical Male Circumcision Regional Report. Katima Mulilo, Zambezi Region, Namibia.

Nanteza, B. M., Serwadda, D., Kankaka, E. N., Mongo, G. B., Gray, R., \& Makumbi, F. E. (2018). Knowledge on voluntary medical male circumcision in a low uptake setting in 
northern Uganda, 1-7.

On, P., Circumcision, M., \& Hiv, F. O. R. (2010). Ministry of Health and Social Services Republic of Namibia Ministry of Health and Social Services Republic of Namibia Ministry Health and Social Services POLICY ON MALE of CIRCUMCISION, (September).

Sknolik, L., Tsui, S., Ashengo, T.A., Kikiya, V. \& Lukobo-Durrell, M. (2014). A cross-sectional study describing motivations and barriers to voluntary medical male circumcision. Retrieved 20 December 2018, from http://www.europepmc.org/articles/PMC4287583

Steytler, D. J. (2014). 2011 population and housing census: Zambezi Regional tables based on 4 th Delimitation, 1-75. Retrieved from http://cms.my.na/assets/documents/p19dptss1rdje1u2jebt1itfraqe.pdf

The Namibia Ministry of Health and Social Services, \& Namibia Statistics Agency. (2014). Namibia Demographic and health Survey 2013, 1-530. Retrieved from http://dhsprogram.com/publications/publication-fr298-dhs-finalreports.cfm\%0Ahttps://dhsprogram.com/pubs/pdf/FR298/FR298.pdf

Unaids. (2007). Male circumcision: global trends and determinants of. Wj790, UNAIDS/07., 13. https://doi.org/10.1097/00002030-199402000-00002

WHO. (2009). Benefits and risks of male circumcision. Manual of Male Circumcision under Local Anaesthesia, 1, Chapter 1-3. 